\title{
Environmental Negotiation: Its Potential and Its Economic Efficiency*
}

\author{
Richard C. Porter \\ University of Michigan, Ann Arbor, Michigan 48109 \\ Received March 28, 1983; revised November 18, 1985
}

\begin{abstract}
Negotiation is increasingly viewed as a desirable alternative to courtroom conflict between industrialists and environmentalists. The "court battle" is often costly, time-consuming, uncertain, and all-or-nothing; negotiation promises a cheaper, quicker, mutually acceptable outcome. This paper examines the conditions under which there is scope for a negotiated compromise; and it examines the conditions under which a negotiated compromise is economically efficient. Its principal result is a warning: there is no reason to expect that environmental negotiation conducted under threat of court battle will produce a socially desirable outcome.

(c) 1988 Academic Press, Inc.
\end{abstract}

Mediation should by all means be encouraged. It can have a valid and important place in the early stages of disputes that revolve around such issues as the exact location of a power plant or dam, or the time schedule an industry might be allowed for abating an environmental nuisance.... Clearly, the more cases that can be settled without recourse to the judiciary, with all its cost and delay, the better.

New York Times

31 August 1977

\section{INTRODUCTION}

Quietly, during the 1970s, a change occurred in the way environmental disputes were settled. Instead of fighting to the end in the courts, bureaucracies, or legislatures, environmental groups and their industrial opponents increasingly sought to negotiate a settlement in which some environmental damage is accepted in return for more extensive environmental safeguarding than the industrialist had originally planned. ${ }^{1}$

The disadvantages of the "court battle" are clear. It is costly, time-consuming, and uncertain as to its outcome. Moreover, it tends to be all-or-nothing, with one party ultimately awarded total victory and the most feared outcome visited upon the loser. Against this can be set the equally clear advantages of a negotiated (or mediated) solution. It is fast (as speedy as the parties wish it to be), inexpensive (relative to litigation), flexible (in the sense that the real, rather than just the litigable, issues can be addressed), and voluntary (in the sense of being mutually

*This research was supported in part by a Sloan Foundation grant awarded to the Institute of Public Policy Studies at the University of Michigan. This paper has benefited from the comments of several members of the Public Finance Seminar at the University of Michigan during presentation of an early version.

'This shift is documented in Gladwin [3, p. 266]. 
acceptable). ${ }^{2}$ It is therefore not surprising to find that most analysts of environmental negotiation sing its praises. It has been extolled as "a positive-sum exercise" and "a much more efficient means [than court battles] of reconciling... most environmental disputes." Susskind et al. [9] pronounce "that an extra-legislative and a non-judicial approach to resolving environmental disputes is infinitely preferable" [p. 24].

The role of this paper is to introduce a cautionary note. Examination of the legal and economic characteristics of environmental disputes indicates that there is no scope for successful negotiation in many circumstances, and, more critically, there is no reason for believing that a negotiated settlement will be economically efficient. This paper shows three potential sources of failure from the viewpoint of economic efficiency. One, negotiation may lead to the wrong (either excessive or inadequate) amount of environmental safeguards being embodied in a project. Two, environmental negotiation may fail to reach agreement on projects that are beneficial when judged from an overall social perspective. And three, negotiation may succeed in producing an agreement to proceed on a project that is undesirable from an overall social perspective. In short, while a successful negotiation must by definition make each of the participants better off than the expected courtroom outcome, there is no guarantee that such a negotiation will produce economically efficient outcomes.

The approach of the paper is as follows. In Section 2, a taxonomy of legal and economic characteristics of environmental disputes is developed. One set of such characteristics is then analyzed in Section 3 as a "basic" environmental dispute. In Section 4, three variations of this environmental dispute are examined. One, the inclusion of side payments, in either direction, is considered. Two, the assumption is dropped that environmental safeguards are available with diminishing returns in terms of the environmental damage they prevent. And three, a less extreme courtroom outcome is explored.

\section{TAXONOMY OF ENVIRONMENTAL NEGOTIATIONS}

During the 1970s, negotiations became increasingly common as a means of attempting settlement of environmental disputes. Innumerable such efforts have now been recorded, concerned with a wide variety of development projects and environmental impacts. Nevertheless, a taxonomy of potential negotiating situations can be constructed by focusing on the legal and economic characteristics rather than the material and ecological attributes. Most industrial/environmental disputes that lead either to court resolution ${ }^{5}$ or to negotiated settlement can be categorized in terms of four features of the conflict.

One, it makes a difference whether the environmental damage $(D)$ that the development project will generate (or is generating) is related to the extent of the

\footnotetext{
${ }^{2}$ The list and many of the words are from Mernitz [5, pp. 47-50]. This book and the works of Susskind and Lake (see [4, 7-10]) offer the best reviews of the process of environmental mediation and examples of its success.

${ }^{3}$ I. W. Zartman, quoted in Lake [4, p. 58].

${ }^{4}$ Susskind $[7$, p. 8$]$.

${ }^{5}$ We shall usually talk for brevity of "court battle," but the same analysis would apply to a distant, uncertain, and arbitrary administrative or legislative decision.
} 
environmental safeguarding $(S)$ in convex fashion or not. ${ }^{6}$ By convex, I mean that the collection of potential safeguards can be arrayed so that they at first reduce environmental damage dramatically but face ever decreasing returns in this respect. ${ }^{7}$ Not all projects can be expected to display such a relationship. It is possible that small values of $S$ cannot much affect $D$, but at some higher value significant impact is realized.

Two, it makes a difference whether the negotiation can involve transfer (or side) payments $(P)$ between the parties. ${ }^{8}$ A negotiated settlement usually specifies that the industrialist can start (or continue) operations provided that a certain amount of environmental safeguarding $(S)$ is implemented. Side payments may or may not be involved. They may be prevented by legal or moral obstacles, by transaction costs, by unclear rights, by the ill-defined membership of the relevant group of "environmentalists," or by the fear of inducing a proliferation of new claimants for such payments. And payments by environmentalists (i.e., $P<0$ ) may also be precluded by a free-rider disincentive if the group is large and diverse.

Three, it makes a difference whether the dispute involves a new development with external environmental costs or an attempt to prevent an already operative project from continuing to generate its traditional environmental impacts. In the first case, a court victory by the industrialist means a new set of resource flows, including new environmental damages, while a victory by the environmentalists ensures a continuation of the status quo. In the second case, the reverse is true: a court victory by the industrialist means a continuation of the status quo, while victory by the environmentalists implies an altered set of resource flows, including reduced environmental damages. These differences in court outcomes provide a critically different backdrop to the negotiating process. Going to court (i.e., refusing to negotiate a settlement) means, in the first case, a potential gain and no potential loss for the industrialist and, in the second case, a potential gain and no potential loss for the environmentalists, when the outcomes are viewed in relation to the continuation of the status quo. ${ }^{9}$

And four, it makes a difference how much safeguarding and side payments-i.e., the sum of $S$ and $P$-the court would impose on the industrialist should the industrialist lose the case. Let the court-set figures be $S_{c}$ and $P_{c}$, respectively. Then, if $\left(S_{\mathrm{c}}+P_{\mathrm{c}}\right)$ exceeds the profitability (II) of the project, the industrialist will not initiate the project and the environmental damage will be zero, but at the cost to the industrialist (and society) of the foregone profit; if $\left(S_{\mathrm{c}}+P_{\mathrm{c}}\right)$ is less than $\Pi$, however, the project will be undertaken, albeit at a cost in terms of environmental

\footnotetext{
${ }^{6}$ Both the damage $(D)$ and the safeguards $(S)$ can, in principle, be expressed in (real) dollar terms; I assume that they can be so measured in fact. Throughout, all variables refer to the present values at the time the project is initiated if a time stream is involved.

${ }^{7}$ More precisely, convexity means $D^{\prime}<0$ and $D^{\prime \prime}>0$, where the primes represent derivatives when $D$ is written as a function of $S, D(S)$. It is possible that $D$ may be reduced to zero with some finite expenditure of $S$, but it seems more typical to think of $D$ approaching some positive minimum level at which $D^{\prime}$ and $D^{\prime \prime}$ become zero.

${ }^{8}$ We define $P>0$ to be a payment by the industrialist to the environmentalists and $P<0$ to be a payment by the environmentalists to the industrialist.

${ }^{9} \mathrm{I}$ am ignoring here, and will throughout, any legal costs involved in the court fight or the negotiation (and hence the distribution of court costs between winning and losing litigants) and any risk aversion that might cause a preference for a negotiated solution to a court outcome of equal expected value. These may be, but are not necessarily, relevant to particular cases, and I want to focus on what I feel are more basic concerns.
} 
damage $\left(D_{\mathrm{c}}\right){ }^{10}$ Furthermore, if less dramatically, expectations about what the court might set in its determination $\left(S_{\mathrm{c}}\right.$ and $P_{\mathrm{c}}$ ) will affect the bounds of possible negotiated settlements. In general, higher expected values of $P_{c}$ and $S_{c}$ will make, ceteris paribus, the industrialist more willing to negotiate and the environmentalists less willing. Thus, both the likelihood and the efficiency of a negotiated outcome may be affected.

From these four different kinds of attributes of environmental disputes, each with (at least) two different possible values, one could taxonomically examine many potential types of disputes. Such a path, however, would produce more tedium than insight. Here we will follow a shorter route. In Section 3, we closely examine a basic and common situation where (1) a new industrial project is proposed, (2) no side payments enter the negotiation, (3) the environmental damage/safeguards relation is convex, and (4) if the dispute goes to court, either the industrialist will proceed without any safeguards or the project will be completely precluded. In Section 4, we look more briefly at the way the negotiating process and the efficiency of the outcome may be altered when these basic attributes are varied.

\section{A BASIC ENVIRONMENTAL DISPUTE}

From the taxonomy of the previous section, let us begin by considering the following ("basic") environmental conflict. An industrialist wishes to undertake a project that will yield private profit (II) and will cause external environmental damage $(D)$. No other effects are foreseen. It would be possible to alleviate the damage by including costly environmental safeguards $(S)$ in the design of the project, although with diminishing returns (i.e., a convex relation between $D$ and $S$ ). Environmentalists are upset at the industrialist's original plan to include no safeguards and threaten court action." Such an action would result in either the industralist receiving the right to proceed as originally planned $(S=0)$ or the project being forbidden totally; the law is sufficiently vague or complex that it is currently unclear which result would emerge. Direct negotiation between industrialist and environmentalists is being attempted, but-for some reason-this negotiation is only about the safeguards $(S)$, with direct bribes (side payments) not being considered $(P=0)$. How likely is this negotiating effort to succeed? And if it succeeds, is there reason to think that the public interest will be served?

We can look at this project from three different viewpoints, the industrialist's, the environmentalist's, and "society"s," where this last comprises both the industrialist and the environmentalists in a straightforward additive way. ${ }^{12}$

A. Industrialist. The project's entrepreneur gains the excess of revenues over direct private costs that the project yields $(\Pi)$; the industrialist would also have to pay for any safeguards that are agreed to. Thus, the present value of the industri-

\footnotetext{
${ }^{10} D_{\mathrm{c}}<D(0)$ assuming $S_{\mathrm{c}}>0$, where $D_{0}(=D(0))$ refers to the environmental damage that remains despite the industrialist's originally planned level of safeguards.

${ }^{11}$ I define the original plan as containing zero safeguards $(S=0)$ although industry is rarely so callous. More precisely, $S$ refers throughout to additional safeguards (i.e., beyond the industrialist's originally planned level).

${ }^{12}$ By this means $I$ ignore both third-party concerns and the possibility that the industrialist and environmentalists are not equally valued in society's objective function. The assumption of a single, defined, homogeneous environmental opposition group is admittedly a substantial abstraction.
} 
alist's profit $\left(P V_{\text {ind }}\right)$ is

$$
P V_{\text {ind }}=\Pi-S .
$$

The profit-seeking industrialist would prefer to set $S=0$, proceed with the project, and earn $\Pi{ }^{13}$

B. Environmentalists. The single impact of the proposed project, from this group's viewpoint, is its environmental damage; ${ }^{14}$ hence the present value to the environmentalists $\left(P V_{\text {env }}\right)$ is

$$
P V_{\text {env }}=-D(S) .
$$

The environmentalists would clearly prefer that the project be proscribed, or, if it is undertaken, that great environmental safeguards be applied, so as to minimize $D$. Note that there are two sources of conflict between environmentalists and industrialist-one, whether the project should be done at all, and two, if it is done, how much environmental safeguarding should be implemented.

C. Society. Since society here is literally the sum of its members, the present value of social profit $\left(P V_{\text {soc }}\right)$ is

$$
P V_{\text {soc }}=\Pi-S-D(S) .
$$

The correct social decision about this project involves two questions. First, if the project were to be undertaken, what would be the optimal amount of safeguarding? The first derivative of (3) with respect to $S$ informs us that

$$
D^{\prime}\left(S^{*}\right)=-1,
$$

where $S^{*}$ is the socially optimal value of $S^{15}$ This optimization at $S^{*}$ and $D^{*}$ is shown graphically in Fig. 1, where the dashed (minus) 45-degree line tangent to the solid-line $D(S)$ curve indicates the least-cost sum of $S$ and $D$. The second question is, if the project design were to contain the optimal safeguarding $\left(S^{*}\right)$, should it be undertaken? The answer, seen in (3), is yes if

$$
\Pi-S^{*}-D\left(S^{*}\right)>0 .
$$

In terms of Fig. 1, condition (5) is fulfilled if $\Pi$, measured along the horizontal axis, lies to the right of the point where the dashed 45-degree line meets the axis.

Unfortunately, this omniscient social decision-making process is usually unavailable. Rather, environmentalists and the industrialist must seek a decision concerning the project in one of two ways, court battle or negotiation.

\footnotetext{
${ }^{13}$ I assume that $\Pi>0$.

${ }^{14} \mathrm{By}$ thinking of this as a marginal project in the economy, we can ignore the possibility of changes in factor rent or consumer surplus that might accrue to environmentalists in their concomitant roles as factors or consumers. Notice that we thereby set aside an interesting complexity of real-world conflicts, where the environmentalists are fighting not only an industrialist but also potential employees who would earn higher wages and/or landowners who would realize capital gains.

${ }^{15}$ The equal sign of (4) assumes an interior solution. $S^{*}=0$ or $D^{*}=D\left(S^{*}\right)=0$ are of course possible corner solutions.
} 


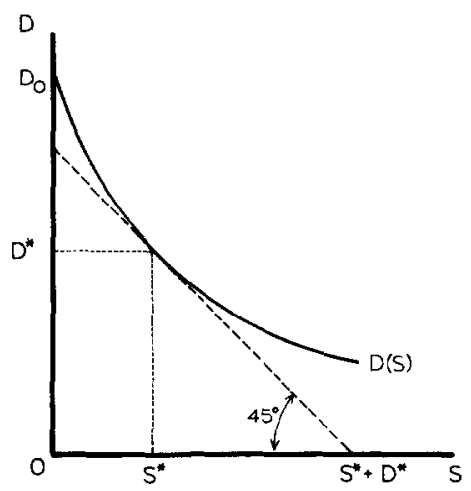

FIGURE 1

First, consider an all-or-nothing court battle. It alternately rages and dallies for years, at the end of which either the industrialist receives the green light to proceed without safeguards or the environmentalists finally block the project. Assume that both industrialist and environmentalists identically perceive the probability of an ultimate victory by the developer as $p$ (where $0<p<1$ ) and that this probability is unrelated to the (economic) merits of the case. ${ }^{16}$ The expected present values of gain (EPV) of the two protagonists through such a court battle are

$$
\mathrm{EPV}_{\text {ind }}=\kappa \Pi
$$

and

$$
\mathrm{EPV}_{\mathrm{env}}=-\kappa D_{0}
$$

respectively, where $\kappa=p(1+r)^{-N}, r$ is the discount rate, $N$ is the expected length of the court battle, and all these parameters are assumed to be the same for industrialist and environmentalists. Notice that both uncertainty $(p<1)$ and delay $\left((1+r)^{-N}<1\right)$ operate to reduce the industrialist's expected present value of gain below $\Pi$. The same two factors operate in the same way to reduce the expected present value of environmental damage, but the damages that might eventually emerge are the highest possible since, if the developer wins, $S=0$.

The alternative to this court proceeding is negotiation, which entirely removes both uncertainty and delay. ${ }^{17}$ Is there scope for such negotiation? The industrialist would prefer to incur negotiated safeguards of $S_{\mathrm{n}}$ as long as the profit that remains after negotiation exceeds the expected profit from the court battle, i.e., if

$$
S_{\mathrm{n}}<(1-\kappa) \Pi \text {. }
$$

\footnotetext{
${ }^{16}$ Note that identical perceptions of $p$ do not necessarily mean correct perceptions of $p$-the latter are irrelevant to the scope for and efficiency of negotiation. We will look later in this section at the effect of different perceptions. Those who find the Bridlegoose-like approach to court decisions in environmental matters excessively caustic may think of the probabilistic assumption as "simplifying"; but also be reminded that the law in these matters is often new and still unclear and that decisions are regularly made on obscure procedural grounds.

${ }^{17}$ Of course, negotiation also takes time, but less time. Nothing important is lost by assuming it takes no time.
} 

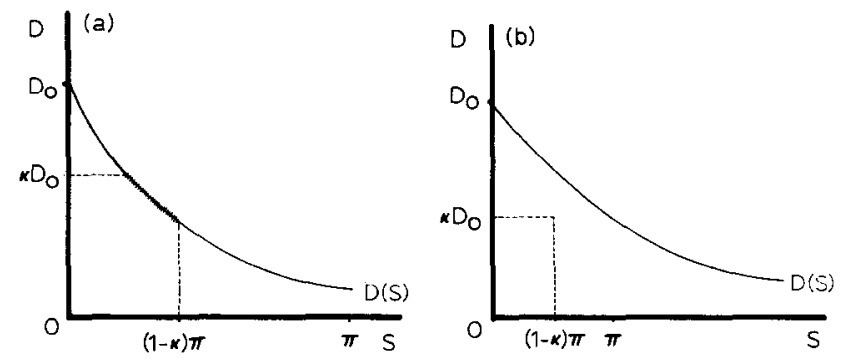

Figure 2

Similarly, the environmentalists would prefer to negotiate as long as

$$
D_{\mathrm{n}}<\kappa D_{0},
$$

where $D_{\mathrm{n}}=D\left(S_{\mathrm{n}}\right)$. Inequalities (8) and (9) are graphed in Fig. 2. Figure 2a shows a situation in which there is scope for negotiation-both parties are better off (than with court battle) with any values of $S_{\mathrm{n}}$ and $D_{\mathrm{n}}$ along the hatched part of the $D(S)$ curve. Figure $2 \mathrm{~b}$ shows a situation in which there is no negotiated value of $S_{\mathrm{n}}$ that leaves both better off.

What aspects of the environmental disputes make negotiated solutions possible, as in Fig. 2a, or impossible, as in Figure 2b? Clearly, the more there is to gain ( $\Pi$ ) or lose $\left(D_{0}\right)$, the more likely is a negotiated solution. ${ }^{18}$ Also, the "scope" for compromise is increased by a more convex shape to the $D(S)$ function. Finally a negotiated settlement is made more likely by a "middling" value of $\kappa$; as either the environmentalists or the industrialist becomes more certain of a total and quick court victory, there is less "room" on the $D(S)$ function for an acceptable compromise.

As an aside to the theory, but important in fact, we should notice the effects on the prospects for a negotiated settlement of differing perceptions of $\kappa$ by the two parties. If environmentalists are overly optimistic about their chances of winning in court, or of prolonging the court battle, that lowers the $\kappa D_{0}$ constraint in Figs. 2a and $2 b$ and reduces the scope for negotiation. Similarly, excessive optimism by the industrialist moves the $(1-\kappa) \Pi$ constraint leftward and reduces the scope for negotiation. One could make a case, based for example on the incentive structure facing the various lawyers involved, that such bias is likely to appear, at least initially, and that such bias will often prolong or even preclude objectively feasible negotiations. ${ }^{19}$ Of course, risk aversion, which is ignored by the theory here but may be important in fact, works in the opposite direction.

Is there any reason for thinking that an out-of-court settlement, if negotiated, will be socially optimal? The answer is simple: no. Inspection of Fig. 2 readily reveals that the marginal condition (4) for the social optimality of safeguards will not in general be reached by negotiation. There is nothing in the two inequalities, (8) and (9), that involves $D^{\prime}(S)$, and there is no reason for thinking a negotiated $S_{\mathrm{n}}$ will be exactly that value at which the marginal optimality condition (4) is met. Indeed, as

\footnotetext{
${ }^{18}$ Note that constraints (8) and (9), as drawn in Fig. 2, intersect along a straight line from point $\left(0, D_{0}\right)$ to point $(\Pi, 0)$.

${ }^{19}$ See, for example of this, Michigan's Pigeon River dispute [1].
} 

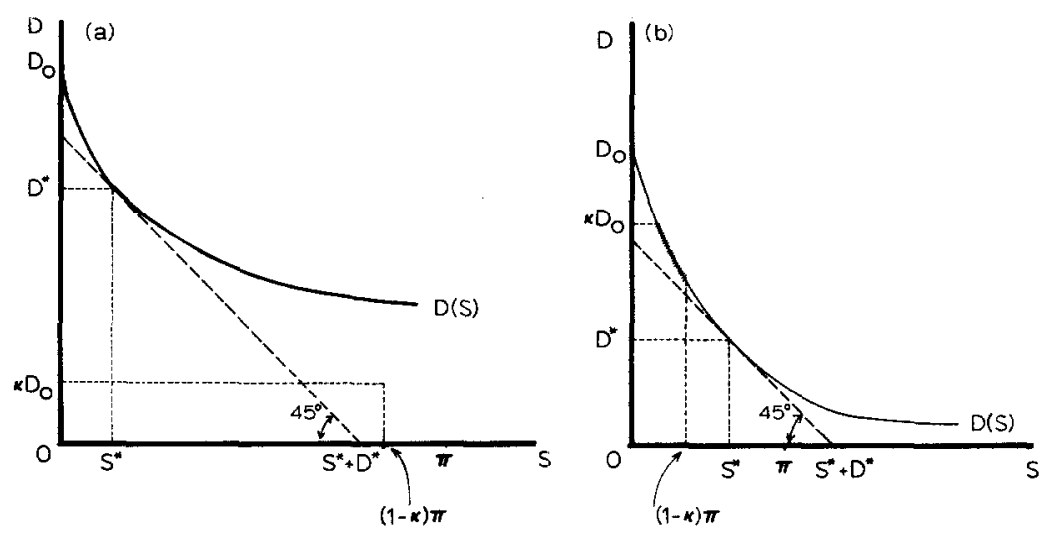

FIgURE 3

Fig. 2a is drawn, the entire hatched region fails to include the values of $D$ and $S$ where condition (4) is fulfilled; and, as Fig. $2 \mathrm{~b}$ is drawn, no negotiated solution is feasible despite the existence of a point on the $D(S)$ curve at which condition (4) is satisfied. Of course, this marginal condition (4) will not in general be reached by court battle either. But there is no reason for thinking that negotiation will come even close to achieving $D^{\prime}=-1$.

There is also no reason for expecting in general that environmental negotiation will be consonant with the total condition (5) for social optimality. It is easy to show this by counterexamples, first, of a socially profitable project that nevertheless offers no scope for negotiation, and second, of a socially unprofitable project that nevertheless offers considerable scope for negotiated approval. These two counterexamples are shown, respectively, in Figs. $3 a$ and $3 b$.

In Fig. 3a, the private profit exceeds the sum of the (optimal) safeguarding and environmental costs. The two social optimality conditions (4) and (5) are both satisfied if the project proceeds with proper safeguards, $S^{*}$. But the inequalities (8) and (9) are such that there is no scope for negotiation-no value of $S_{\mathrm{n}}$ minimally satisfies both parties simultaneously. Attempts at negotiation are doomed, and the fate of the project will be determined in court. Why does negotiation fail? Algebraically, in Fig. 3a, it is the low value of $\kappa$ that does $i^{20}$; either the chances of the environmentalists in court are very good (i.e., low $p$ ) or the court battle promises to be a long one (i.e., high $N$ ). As a result, the environmentalists' minimally acceptable $S_{\mathrm{n}}$ is larger than the industrialist is willing to concede.

In Fig. 3b, a different example is illustrated, where a socially undesirable project may nevertheless be implemented after negotiations between industrialist and environmentalists. Even with the optimal level of safeguards $\left(S^{*}\right)$, the indirect environmental costs, $S^{*}+D^{*}$, exceed the direct private profit, $\Pi$, and the project should be rejected. But when the court is likely to decide for the industrialist (i.e., when $\kappa$ is high), there is scope for a negotiated approval of the project. One such value of $\kappa$ is incorporated into Fig. 3b, and the hatched region of the $D(S)$ curve

${ }^{20}$ To see this, draw a straight line from $D_{0}$ to $\Pi$. A sizable portion of that line falls above the $D(S)$ curve. A value of $\alpha$ that leads to a point on this line above and to the right of the $D(S)$ curve would leave scope for a negotiated settlement. 
shows the range of mutually acceptable negotiated levels of safeguards. ${ }^{21}$ How can this perverse result come about? Everybody seems to be better off as a result of the negotiation despite the economic inefficiency of the project! But recall that the choice is not between a negotiated project and no project at all or between a negotiated project and a project with no safeguards, all according to the ownership of rights (à la Coase [2]), but between a negotiated project and an uncertain court battle. And in court, in the case shown in Fig. 3b, not only is a quick victory for the developer likely (i.e., high $k$ ) but also the environmental damage that would follow such a victory is very high (i.e., high $D_{0}$ ).

In summary to this point, there is no reason to expect socially efficient results from environmental negotiation when it occurs under threat of an alternative, uncertain, time-consuming means of decision-making that is itself not necessarily socially efficient. Potentially good projects may not find their successful way through the negotiations, and surely bad projects may be approved through negotiated settlement. ${ }^{22}$ Moreover, nothing in the negotiating process ensures that the optimal level of environmental safeguards will be arrived at. The negotiated settlement will obviously be better, for industrialist, for environmentalists, and for society, than the expected courtroom result, but there is no intrinsic assurance that it will be better than the actual court outcome.

\section{VARIATIONS ON THE BASIC DISPUTE}

Three variations on the "basic" environmental dispute will be examined in turn: (1) the possibility of side payments is introduced; (2) a non-convex damage function is considered; and (3) an alternative, less extreme than all-or-nothing, courtroom outcome is explored. ${ }^{23}$

A. Side payments. When the various legal and economic barriers to side payments can be overcome, a new degree of freedom is introduced into the negotiation process. Between the industrialist who wishes to initiate a privately profitable project and environmentalists who object to the concomitant environmental damage, the alternative to court battle is a negotiation that determines two things, the amount of environmental safeguarding $\left(S_{n}\right)$ and the size of the side payment $\left(P_{n}\right)^{24}$

Except for the possibility of side payments, we stay with the "basic" case of Section 3 with a convex environmental damage function and an all-or-nothing courtroom possibility in which the project will be either barred entirely or launched with no safeguards at all. The expected present values through the court battle are thus the same as in the "basic" case of Section 3, Eqs. (6) and (7). The alternative to

\footnotetext{
${ }^{21}$ All these negotiated values of $S_{\mathrm{n}}$ are less than $S^{*}$ for the $\kappa$ shown in Fig. 3b, but that is not necessarily the case for all lower values of $\kappa . S_{n}>S^{*}$ is possible although, of course, $S_{n}>\Pi$ is not possible.

${ }^{22}$ By "potentially good," I mean one that would be socially profitable if the optimal level of safeguards were adapted-i.e., when both conditions (4) and (5) are met. By "surely bad," I mean one that would be socially unprofitable even with the optimal level of safeguards-i.e., condition (5) is not met even when condition (4) is met.

${ }^{23}$ Variation on the fourth characteristic enumerated in Section 2, whether the dispute is over a proposed or existing project, yields no interesting information. The potentials for negotiation and the caveats about efficiency depend on the same factors in the same ways.

${ }^{24}$ This payment could be in either direction, i.e., $P_{\mathrm{n}} \gtreqless 0$. (Recall our convention: $P_{\mathrm{n}}>0$ means a payment by the industrialist to the environmentalists, $P_{\mathrm{n}}<0$ a payment in the reverse direction.)
} 
this court battle is a negotiated settlement, whereby the industrialist ends up with a present value of $\Pi-S_{\mathrm{n}}-P_{\mathrm{n}}$ and the environmentalists with a present value of $P_{\mathrm{n}}-D_{\mathrm{n}}$.

No algebra is needed to see that any negotiated solution must achieve marginal efficiency. Until $D^{\prime}=-1$, there is always room to make both parties better off by adjusting $S_{\mathrm{n}}$ toward $S^{*}$ and appropriately altering the side payment, $P_{\mathrm{n}^{*}}$. Thus, the question whether successful negotiation is possible reduces to the question whether there is a side payment at $S^{*}$ (and $D^{*}$ ) that betters each party, relative to its EPV from court resolution. Such betterment requires

$$
\Pi-S^{*}-P_{\mathrm{n}}>\kappa \Pi
$$

and

$$
-D^{*}+P_{\mathrm{n}}>-\kappa D_{0}
$$

or, combining and rearranging,

$$
D^{*}-\kappa D_{0}<P_{\mathrm{n}}<(1-\kappa) \Pi-S^{*} .
$$

Some-possibly positive, possibly negative-values of $P_{\mathrm{n}}$ will satisfy (16) provided that

$$
D^{*}+S^{*}<\kappa D_{0}+(1-\kappa) \Pi \text {. }
$$

Clearly, from (17), socially profitable projects are negotiable. ${ }^{25}$ It would appear at first glance that at least some socially unprofitable projects are also negotiable. For example, consider $D_{0}>D^{*}+S^{*}>\Pi$ and $\kappa=1$ (or close to it); condition (17) is met, despite the undesirable nature of the project. But then there remains further scope for bettering each disputant by just not doing the project-environmentalists will be better off with a negotiated settlement in which the industrialist receives the larger of the $\mathrm{EPV}_{\text {ind }}$ of $\kappa \Pi$ (Eq. (6)) or the negotiated profit of $\Pi-S^{*}-P_{\mathrm{n}}$ (inequality (14)) from the environmentalists in return for withdrawing the project. ${ }^{26}$

The possibility of side payments leads the negotiation to the efficient result, marginally and totally. But recall that this conclusion requires for generality that there be no restriction on the sign or size of the side payment. Once side payments cannot be arranged from environmentalists to industrialists (i.e., $P \geqslant 0$ only) or must be "modest" in size, we begin to move toward the "basic" kind of dispute (Section 3), and the possibility begins to emerge that bad projects will be negotiated successfully or that good projects will fail to be negotiated. ${ }^{27}$ This suggests two things. First, environmental negotiators should be urged to consider side payments as well as safeguards. And second, where no side payments occur in a successfully negotiated settlement, we should worry about the possibility that constraints on side payments have prevented a socially desirable result.

\footnotetext{
${ }^{25} D^{*}+S^{*}<\Pi$ (definition of social profitability) and $D^{*}+S^{*}<D_{0}$ (definition of least-cost safeguards); so $D^{*}+S^{*}$ must be less than a weighted average (by $\kappa$ and $1-\kappa$ ) of the two.

${ }^{26}$ This is seen most easily by noting that not doing the project at all recaptures the project's social losses, $S^{*}+D^{*}-\Pi$, which is the pie to be divided between the two.

${ }^{27}$ Linking two disputes together for negotiation provides a kind of possibility of side payment-giving up one to get the other-but such lumpy side payments do not necessarily achieve socially efficient outcomes [6].
} 

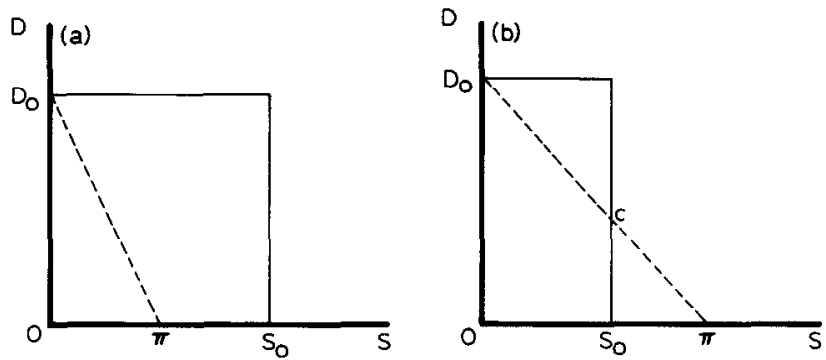

Figure 4

$B$. Non-convex damage function. We turn now to the project whose environmental damage is non-convex, and for simplicity we will consider the extreme version of such non-convexity that is pictured in Figs. $4 \mathrm{a}$ and $4 \mathrm{~b}$. If no safeguards are taken the damage will be $D_{0}$, and the only safeguarding available is some indivisible activity that costs $S_{0}$ and entirely alleviates the damage. In Fig. 4a, the safeguard cost $\left(S_{0}\right)$ exceeds the private profit $(\Pi)$ of the project, while in Fig. $4 \mathrm{~b}$ it is less. Otherwise, the dispute is similar to the "basic" case: the project is proposed; if it goes to court, the industrialist will either be permitted to proceed without safeguards or be barred entirely from the undertaking; and side payments do not enter the negotiation.

The conditions under which negotiating efforts have scope for success are readily derived. Court battle yields, as in the "basic" case, Eqs. (6) and (7). Negotiation improves each party's lot if, as in the "basic" case, inequalities (8) and (9) hold. Depending on the value of $\kappa$, these constraints (8) and (9) form a rectangular feasible area bounded on the south and west by the axes and with a northeastern vertex somewhere along the dashed line from $D_{0}$ to $\Pi$.

In Fig. 4a, no negotiation is feasible - a court battle will surely ensue. And yet, if $\Pi>D_{0}$, the project is socially efficient; negotiation cannot promote it, and the court can offer no more than a probability of its eventual realization.

In Fig. 4b, on the other hand, there is a possibility of successful negotiation if $\kappa$ is low enough that the feasible rectangle is bounded to the northeast by a point between points $c$ and $\Pi{ }^{28}$ The profit then is sufficiently great that the industrialist would rather spend the $S_{0}$ now than risk the loss of $\Pi$ later. The negotiation is efficient in that it assures the launching of a desirable project $\left(\Pi>S_{0}\right)$. But it does not assure the correct amount of safeguarding; the safeguarding should be zero or $S_{0}$ according as $S_{0} \gtrless D_{0}$, while any negotiation always leads to $S_{0}$.

Thus, non-convexity poses a hurdle to negotiation, perhaps insurmountable without side payments. ${ }^{29}$ Bad projects cannot be successfully negotiated, but good

${ }^{28}$ By "low enough" is meant

$$
\kappa<\frac{\Pi-S_{0}}{\Pi} .
$$

${ }^{29}$ The interested reader can easily show that the efficient outcome always emerges here if unconstrained side payments are possible-profitable projects will be negotiated and with the correct choice of safeguards. 
projects may either fail to be negotiated altogether or fail to be negotiated with the correct level of safeguards.

C. Alternative courtroom outcomes. So far, we have been assuming that the threatened court encounter, should it occur, will result in one of two rather extreme outcomes. Either the project will proceed, totally unencumbered by environmental safeguards, or it will be irretrievably rejected, regardless of its unexplored potential for safeguards. Courts need not make such extreme decisions, although their adversarial character and procedural priorities rarely make them ideal locations for finely tuned efficiency decisions. In this section, we will examine two less extreme outcomes, namely, where the court will ultimately permit the project but will set different degrees of environmental safeguards depending on who wins the case. ${ }^{30}$ If the industrialist wins, the project will be approved with safeguards $\left(S_{\mathrm{c}}\right)$, and if the environmentalists win, the project will be approved with a different set of safeguards $\left(S_{\mathrm{c}}^{\prime}\right)$. The interesting case is that in which $0<S_{\mathrm{c}}<S_{\mathrm{c}}^{\prime}<\Pi$.

Consider a newly proposed project, a convex environmental damage function, and the impossibility of side payments in negotiations. Then the courtroom expectations are

$$
\mathrm{EPV}_{\mathrm{ind}}=\kappa\left(\Pi-S_{\mathrm{c}}\right)+\kappa^{\prime}\left(\Pi-S_{\mathrm{c}}^{\prime}\right)
$$

and

$$
\mathrm{EPV}_{\mathrm{env}}=-\kappa D_{\mathrm{c}}-\kappa^{\prime} D_{\mathrm{c}}^{\prime}
$$

where $\kappa^{\prime}=(1-p)(1+r)^{-N}$, the present value of the probability of an environmentalist victory in court, and where $D_{c}$ and $D_{c}^{\prime}$ are the environmental damages that follow with safeguards, $S_{c}$ and $S_{c}^{\prime}$, respectively. A negotiated solution is possible if

$$
S_{\mathrm{n}}<\left(1-\kappa-\kappa^{\prime}\right) \Pi+\kappa S_{\mathrm{c}}+\kappa^{\prime} S_{\mathrm{c}}^{\prime}
$$

and

$$
D_{\mathrm{n}}<\kappa D_{\mathrm{c}}+\kappa^{\prime} D_{\mathrm{c}}^{\prime}
$$

To keep things less messy, ignore the fact that $\kappa+\kappa^{\prime}<1$ and assume that they do add to one (because either $r$ or $N$ is "very small"). Then the conditions (20) and (21) for negotiation become, respectively,

$$
S_{\mathrm{n}}<\kappa S_{\mathrm{c}}+(1-\kappa) S_{\mathrm{c}}^{\prime}
$$

and

$$
D_{n}<\kappa D_{c}+(1-\kappa) D_{c}^{\prime}
$$

The feasible rectangle for negotiations is thus bounded on the northeast by a point along the dashed line in Fig. 5 (from the point $\left(S_{\mathrm{c}}, D_{\mathrm{c}}\right)$ to the point $\left(S_{\mathrm{c}}^{\prime}, D_{\mathrm{c}}^{\prime}\right)$ )-exactly where will depend on the magnitude of $\kappa$. It is clear that, for any $0<\kappa<1$ and for any $0<S_{\mathrm{c}}<S_{\mathrm{c}}^{\prime}<\Pi$, there are values of $S_{\mathrm{n}}$ (and hence $D_{\mathrm{n}}$ ) that can be

\footnotetext{
here.

${ }^{30}$ Courts could also set side payments $(P)-$ e.g., compensation or fines-but we will ignore these
} 


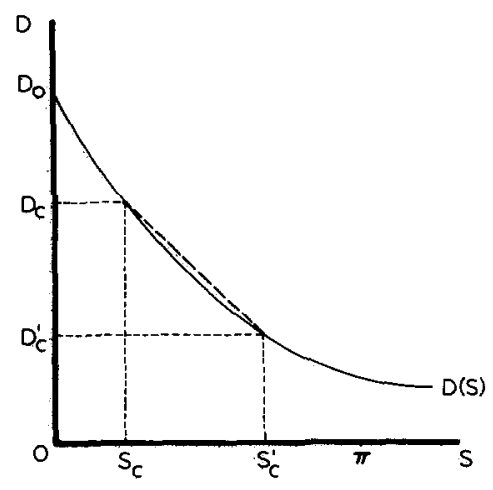

FIGURE 5

negotiated between the parties so that each is better off than with the expected court result. $^{31}$

Thus, when it is known beforehand that the project will survive the court struggle although with an uncertain amount of environmental safeguarding, there is always scope for negotiation. ${ }^{32}$ There is, however, no assurance that the negotiation will lead to an efficient result. The marginal condition $\left(D^{\prime}=-1\right)$ will be met only by coincidence, bad as well as good projects may be successfully negotiated, ${ }^{33}$ and one (but not both) of the possible court outcomes may be socially superior to the negotiated outcome. Judicial finetuning of the safeguarding is only a positive step forward if the court-set levels bracket the socially correct level (i.e., $S_{c}<S^{*}<S_{c}^{\prime}$ ). And increasing the likelihood of negotiated settlement is no virtue if the entire project is intrinsically bad (i.e., $\Pi-S^{*}-D^{*}<0$ ).

\section{SUMMARY}

There is often scope for negotiation over environmental disputes, especially when the alternative is an uncertain, delayed, all-or-nothing courtroom resolution. But such negotiation does not necessarily lead to a socially correct decision, either in terms of the projects undertaken or in terms of the extent of the environmental safeguarding embodied in them. Only if side-payment possibilities exist and are fully exploited can we be certain that environmental negotiation will promote socially desirable projects and that successful negotiation of undesirable projects will be impossible. Without side payments, the negotiating process may fail in any of three ways: (1) approval of socially bad projects may be negotiated; (2) inefficient levels--either excessive or inadequate-of environmental safeguarding may be established through negotiation; or (3) socially good projects may not be negotiable. Negotiation under threat of court battle is no social panacea.

\footnotetext{
${ }^{31}$ This same conclusion is readily shown to hold, a fortiori, if $x+x^{\prime}<1$.

${ }^{32}$ Provided, as inspection of Fig. 5 makes clear, that the damage function is convex.

${ }^{33}$ Projects are "good" or "bad" according as $\Pi-D_{\mathrm{n}}-S_{\mathrm{n}} \gtrless 0$. $S_{\mathrm{n}}$ will be less than $\Pi$, but $D_{\mathrm{n}}+S_{\mathrm{n}}$ may be greater.
} 


\section{REFERENCES}

1. E. Cherner, "The Pigeon River Country State Forest: Benefit-Cost Analysis of Hydrocarbon Development and Analysis of Controversy Resolution," Honors thesis, University of Michigan, Ann Arbor (1982).

2. R. Coase, The problem of social cost, J. Law Econom., October (1960).

3. T. N. Gladwin, Patterns of environmental conflict over industrial facilities in the United States, 1970-78, Natur. Resour. J. April (1980).

4. L. M. Lake (Ed.), "Environmental Mediation: The Search for Consensus," Westview Press, Boulder (1980).

5. S. Mernitz, "Mediation of Environmental Disputes: A Sourcebook," Praeger, New York (1980).

6. R. C. Porter, "Negotiating Linked Environmental Disputes," mimeo, November (1985).

7. L. Susskind, It's time to shift our attention from impact assessment to strategies for resolving environmental disputes, Environ. Impact Assess. Rev. 4 (1978).

8. L. Susskind, Environmental mediation and the accountability problem, Vermont Law Rev. July (1981).

9. L. E. Susskind, J. R. Richardson, and K. J. Hildebrand, "Resolving Environmental Disputes: Approaches to Intervention, Negotiation, and Conflict Resolution," Laboratory of Architecture and Planning, MIT, mimeo, June (1978).

10. L. Susskind and A. Weinstein, "Towards a Theory of Environmental Dispute Resolution," mimeo, 23 June (1980). 